\title{
THE BLINDNESS OF TOBIT
}

\author{
BY
}

ERnest Thomson and R. R. JAmes

IT may well be that readers of this Journal have made no great study of the story of Tobit, his son Tobias and the (reputed) angel Raphael. The story as a whole should, in words familiar to us, " be read in the original," but some speculations regarding the cause and the cure of the blindness of Tobit may form a contrast to the rigid facts of the biochemist.

Tobit lived in Nineveh of Assyria : he was of the captivity and was devoted to his own people. A large-hearted man, one of the ways in which he expressed this devotion was in the pious burial of any one of his people whom he might find slaughtered and " cast out upon the walls" by Enemessar the king. It happened on a day, when he had buried a compatriot that, feeling himself unclean, he preferred to sleep out instead of returning to his house. ". . . and slept by the wall of my courtyard, being polluted; and my face was uncovered: and I knew not that there were sparrows in the wall; and, mine eyes being open, the sparrows muted warm dung into mine eyes; and I went to the physicians and they helped me not.

At this same time it became necessary for Tobias, the son of Tobit, to travel to Rages of Media. The object of the journey was financial and does not seem to have had anything to do, in the mind of Tobias, with his father's blindness. Incidentally, Tobias obtained a wife : but that is " another story " and a very strange one. With Tobias went one, Raphael by name, who declared himself to be an angel sent to help Tobias in various ways. In the course of the journey of Tobias and Raphael, they halted beside the River Tigris when " a fish leaped out of the river and would have swallowed up the young man." Instructed, however, by Raphael, Tobias flung the fish to land and removed the heart, liver and gall and "put them up safely." Tobias, very naturally enquired why this should be done. Raphael the angel replied " Touching the heart and the liver, if a devil or an evil spirit trouble any, we must make a smoke thereof before the man or the woman, and the party shall be no more vexed. But as for the gall, it is good to anoint a man that hath white films in his eyes and he shall be healed."

Eventually Tobias and Raphael (and also Tobias's new wife and his dog) returned to the house of Tobit. It must have been months at the least before Tobias and the angel returned because, at a rough estimate, the journey can hardly have been less than $400-600$ miles. As soon as his father stumbled out to meet him Tobias 
" strake the gall on his father's eyes . . . but when his eyes began to smart, he rubbed them; and the white films scaled away from the corners of his eyes; and he saw his son . . ." Bland Sutton (Selected Lectures and Essays, 4th Edit., 1920), thought that the blindness of 'Tobit was due to cataract and that when Tobit rubbed his eyes he dislocated the lenses. This, of course, is a possible explanation. Bland Sutton considered that Tobit was aged 58 years when he became blind and that the cure took place eight years later. But there does not seem to be any real proof in the story as told in the Apocrypha that the journey was so long as all that; the straightforward account of the journey and the happenings in Media almost negative it, in spite of the statement quoted by Bland Sutton, which is made near the end of the book of Tobit and was quite probably written by a different scribe. The same scribe (apparently) says that Tobit was " a hundred and eight and fifty years old " when he died. Yet his wife was still living and so was Tobias his son. It is more than probable that these chronological statements are not to be trusted at all.

If we take the words of the text, the expression "white films" does not seem a good description of ordinary cataract behind ordinary pupils. Further, it is plain that something happened suddenly to Tobit's eyes and caused him to seek treatment. Whether the vulgar behaviour of the sparrows in blocking up the eyes had anything to do with the attack seems very doubtful. It is much more likely that when attending to his dead fellow countryman some septic or pathological secretion was accidentally introduced by Tobit himself and set up a violent inflammation which caused the eyes to be closed up. This is strongly supported by what Raphael said to Tobias on their return journey ; " I know, Tobias, that thy father will open his eyes ". (after the treatment with gall.) Tobit's eyes must, therefore, have been closed when they left him. People with ordinary cataract do not have their eyes suddenly closed up. Lastly, there is the previously quoted statement, " and the white films scaled away from the corners of his eyes."

It seems almost impossible to accept as a cause of the blindness the explanation about the sparrows. The sparrows would hardly be likely to cause double blindness, even supposing that Tobit had lagophthalmos and had his eyes open in sleep. The "cure" is more interesting. If one assumes that the "white films" were nothing else than secretion in an acute and perhaps afterwards a subacute or chronic ophthalmia (?trachoma) what influence might the gall of a fish have upon the disease? True, the cure reads as if it had been immediate - as would be the case with dislocation of a cataract-but one cannot trust old writings, e.g., in the Bible, to 
be chronologically accurate. There is a distinct and perhaps interesting possibility in cholesterin : it is an active substance in various ways. It is a constituent of gallstones, even up to 90 per cent. or more (Extra Pharmacopoeia, Vol. 1, p. 112, Eighth Ed.) Cholesterin is an unsaturated secondary alcohol having the molecular formula $\mathrm{C}_{27} \mathrm{H}_{46} \mathrm{O}$. It occurs in the organism both in the "free" i.e., alcoholic, condition, and as esters of the fatty acids. We are not prepared to state whether or not this active substance exists in any special form in fish gall, but the investigation may appropriately be left to the chemists, one might say to the biochemists.

One more remark, and this disquisition is finished. What other fish than a salmon could this have been which with "vaulting ambition which o'erleaps itself " falls on the rocks at the side of the leap and is captured by the hands of a young man camped on a rugged portion of the bank of the Tigris? A very human story this. Only the essentials of one part of it have been here referred to.

\title{
IODINE IN THE TREATMENT OF TRACHOMA
}

\author{
BY \\ J. NeumanN \\ FROM THE OPHTHALMIC CLINIC OF THE UNIVERSITY OF WARSAW. \\ DIRECTOR : W. MELANOWSKI
}

THE cure of trachoma is a task which frequently affords serious difficulties. In cases of advanced trachoma, especially when complicated by pannus, ulcers and infiltrates of the cornea, our ordinary methods of treatment often fail. In such cases copper sulphate does not always relieve, it may aggravate the condition; and the long continued use of silver nitrate, though most useful as long as muco-purulent secretion is excessive, usually leads to argyrosis. It is in such cases that I have found the application of iodine successful. I was led to try this drug in a desperate case of trachoma (Case I) and was so much impressed with the favourable result that I have given it a repeated trial in bad cases since, always with good results. This paper concerns 15 cases of trachoma treated with iodine.

\section{Case I}

A male clerk, aged 20 years, consulted me in June, 1926. His left eye had been "sore" since May, 1924; he had undergone treatment at the hands of several physicians and peritomy had 